\title{
O profissional da informação na sociedade do conhecimento: aspectos e proposta para a sua atuação na mediação da informação
}

The professional of information in the knowledge society: aspects and proposal for their role in the mediation of information

\section{Deise Antonio (1) y João Batista Ernesto de MORAEs (2)}

(1) Faculdade de Filosofia e Ciências, Unesp, Av. Higyno Muzzi Filho, 737, Marília, São Paulo, Brasil, CEP: 17525-900, deise@tupa.unesp. br (2) jota@marilia.unesp. br

\begin{abstract}
Resumen
Nuevas perspectivas apuntan a tareas más dinámicas y complejas para el trabajo del bibliotecario. El paradigma en el proceso de comunicación era la mediación proporcionada por el bibliotecario, siendo él uno de los actores en el traslado de información y mediación en la construcción del conocimiento. Por supuesto, ésta no era una mediación neutra, sino dependiente de los espacios institucionales en los cuáles se halla integrado o sumergido. El papel del bibliotecario sería actuar en la estructura del proceso, y entre el emisor/productor y el receptor/consumidor de conocimiento. Con el nuevo paradigma tecnológico, el fenómeno de la desintermediación en las relaciones tradicionales de la comunicación y apropiación del conocimiento es defendido por algunos autores. El papel de mediador del bibliotecario en el canal de flujo de comunicación ha sido cuestionado desde que el usuario puede ser el emisor y receptor de los mensajes, un productor y un usuario de la información. El propósito de este trabajo es discutir los problemas del modelo de actuación del profesional de información en la sociedad de conocimiento, buscando respuesta al problema de si en esta sociedad el modelo de comunicación responde las necesidades de los usuarios, rescatando el papel social del bibliotecario y definiendo características de este profesional. La metodología usada es la investigación teórica a través de la construcción de un marco de referencia de intermediación. Se concluye que el proceso de apropiación de la información y el conocimiento queda comprometido sin la mediación de un profesional.

Palabras clave: Mediación de la información. Bibliotecario educador. Desintermediación.
\end{abstract}

\section{Introdução}

Muitas transformações vêm ocorrendo no papel do profissional da informação decorrentes da nova conjuntura social, econômica e tecnológica impulsionadas pela globalização da informação e dos novos paradigmas culturais e sociais provenientes da sociedade da informação e do conhecimento.

\begin{abstract}
The new context points to more dynamic and complex tasks for the librarian work. The paradigm in the communication process was the mediation provided by the librarian, being one of the actors in the transfer of information and mediation in the construction of knowledge. The role of the librarian was to intermediate actions of communication of information, acting on the structure of the process, and between the emitter/producer of knowledge and the receiver/consumer of knowledge. With the new technological paradigm, the phenomenon of disintermediation in traditional relations of communication and ownership of knowledge is advocated by some authors. The role of mediator librarian in the channel of communication flow has been questioned since the user can be emitter and receiver of messages, a producer and a user of the information. The purpose of this paper is to discuss issues relating to the performance of the model of the professional of information in the knowledge society seeking answer whether in this society the model of communication responds users' needs, rescuing the social role of librarian and defining the characteristics of this work. The methodology used is the theoretical research through the construction of a frame of reference on brokering. The results show that the process of ownership of information and knowledge are committed without the mediation of a professional because the tendency is aggravated by the limitation of reading.
\end{abstract}

Keywords: Information mediation. Educator librarian. Disintermediation.

O novo contexto exige do profissional da informação a apropriação de novas competências e o desenvolvimento de habilidades que proporcionem o êxito do fazer profissional nessa sociedade do conhecimento que depende dos recursos estratégicos da informação. Trata-se de uma "sociedade informatizada, caracterizada por elevadas taxas de produção e consumo de informação de vários tipos, por canais múltiplos, 
pela onipresença midiática e marcada por uma nova comunicabilidade e uma nova sociabilidade" (Oddone, 1998, p. 2). A nova perspectiva aponta para atribuições mais dinâmicas e complexas para o trabalho biblioteconômico.

Uma vez que o profissional da informação (Lima et al, 2006, p. 3)

deve ter habilidade de solucionar problemas, de aprender a aprender, de aprender independentemente, de aprender ao longo de toda a sua vida, de questionamento, de pensamento lógico, dessa forma deve-se insistir que esse profissional chame atenção com esse novo perfil, para desenvolver esse potencial na biblioteca, pois isso irá demonstrar que o novo profissional da informação é também um educador, deixando para trás suas características de passividade e isolamento.

No passado, os bibliotecários eram reconhecidos como eruditos guardiões do conhecimento, bibliófilos, e isso dominou a profissão até o século XIX. Segundo Shera (1980, p. 93) "os bibliotecários eram eruditos que, desde a época de Ptolomeu, fundaram a grande biblioteca de Alexandria, na foz do Nilo, ocupavam-se em reunir e classificar sistematicamente todos os conhecimentos registrados em forma documental, isto é, a transcrição da aventura humana".

Com surgimento da revolução industrial a atuação profissional é marcada pelo domínio de técnicas e procedimentos fazendo sua prática tecnicista e burocratizante. Mas o paradigma no processo comunicacional, ou seja, a mediação proporcionada pelo bibliotecário, era relevante, pois ele era um dos atores na transferência da informação e da mediação na construção do conhecimento. Evidentemente, essa mediação não era neutra, correspondendo aos espaços institucionais aos quais estava integrado ou imerso.

Segundo Oddone (1998, p. 2), o papel do bibliotecário seria o de intermediar as ações de comunicação da informação, agindo na estrutura do processo, estando entre o emissor/produtor do conhecimento e o receptor/consumidor do conhecimento gerado, identificando e atendendo às necessidades informacionais de seus usuários, sejam imediatos ou potenciais, estabelecendo uma dinâmica entre os repositórios estáticos do conhecimento e as questões dos indivíduos na busca de conhecimento.

Com o novo paradigma tecnológico, o fenômeno da desintermediação nas relações tradicionais de comunicação e apropriação do conhecimento é defendido por alguns autores. A Internet, representante mais efusiva das tecnologias da informação e comunicação na sociedade da informação, é considerada a "libertadora" dos usuários da informação no que diz respeito à dependência de intermediários. O papel mediador do bibliotecário no canal de fluxo comunicacional estaria relegado, já que o usuário pode ser emissor e receptor das mensagens, um produtor e um usuário da informação.

\section{Segundo Lopes e Silva (2006, p. 3),}

como usuário da informação, pode escolher entre as informações disponíveis as que lhe interessam em um universo informacional amplo e diversificado e sem passar pelos filtros tradicionais tais como bibliotecas, bibliotecários, editoras, editores.

O objetivo deste trabalho é discutir questões relativas ao modelo de atuação do profissional da informação na sociedade do conhecimento, em função dos novos recursos estratégicos da informação, e discutir se, nesta sociedade, o modelo de comunicabilidade responde às necessidades dos usuários.

Pretende-se demonstrar que, apesar do fenômeno da autonomia dos usuários na busca da informação (desintermediação), o papel do profissional da informação, entendido aqui como bibliotecário, é fundamental como mediador do conhecimento. O objetivo é resgatar o papel social do bibliotecário, bem como definir algumas características para esse profissional da informação, que passar-se-á a entender como bibliotecário educador.

\section{A mediação e a desintermediação da informação}

É importante nesse cenário citar o que Lévy (2000) chama de desintermediação. Para o autor o fenômeno gerado pela Internet e por meio das tecnologias da informação proporcionando a autonomia dos usuários na busca da informação é chamado de desintermediação. Os espaços públicos de comunicação, antes do advento do ciberespaço, eram controlados pelos intermediários institucionais (televisão, rádio, editoras, escolas, bibliotecas) que filtravam e difundiam a informação entre os autores e os consumidores. Lévy $(2000$, p. 210$)$ defende a desintermediação dizendo que

os novos processos de intermediação, em contrapartida, resultam dos próprios indivíduos, e correspondem, de maneira fina, em função de certo trabalhos, às necessidades e aos interesses dos usuários destes [....] a essência da cibercultura está talvez nessa passagem entre seleções, hierarquias e sínteses por toda parte diferentes e em constante mutação conforme as pessoas, os grupos e as circunstâncias.

Mas essa autonomia não é tão autônoma assim, tão livre de mecanismos reguladores como Lévy ressalta no que diz respeito aos espaços institu- 
cionais. Ramonet (2003, p. 243) critica o universo da Internet, no qual as mesclas do texto, do som e da imagem, romperam com as fronteiras das esferas do mundo da mídia, o mundo da comunicação e o mundo da publicidade. Para o autor, na Internet existe esfera da informação, esfera da publicidade e esfera da cultura de massa, mas devido a essa mescla não conseguimos fazer a distinção. É um universo onde há mais televisão, há cada vez mais informação, mais publicidade, sem diferença entre os três, fazendo com que o usuário pense globalmente esses três universos diferentes, em princípio.

Os conteúdos dessas esferas na Internet são controlados, regulados e administrados por empresas que visam à lucratividade sendo os atores principais da globalização. Megagrupos de comunicação surgem como difusores mundiais. É o caso da Time Warner, líder em comunicação, e da América On Line, empresa líder na Internet, que fizeram uma megafusão. No mesmo sentido a compra da Vannesmman pela Vodafone. E, mais recentemente, a compra da comunicade de vídeos You To Be pelo Google Inc.

A questão importante a ser refletida a respeito do uso dessas fontes de informação diz respeito à autonomia do usuário ao acessar conteúdos que são administrados mercadologicamente, por empresas com interesses bem focados, que posicionam seus produtos no mercado de acordo com o comportamento do consumidor. Nesta perspectiva, o usuário não está totalmente isento de mediações e filtros sendo independente na busca de seus interesses.

A informação, nesse universo, pode ser entendida como uma mercadoria, com alta velocidade, chegando ao limite absoluto de aceleração; e gratuita, pois é paga pela publicidade, proporcionando, segundo alguns autores, a dispersão da atenção e a infantilização. Chauí (2006, p. 52) diz que

um dos resultados dessa mudança mental transparece quando crianças e jovens tentam ler um livro: não conseguem ler mais do que sete a dez minutos de cada vez, não conseguem suportar a ausência de imagens e ilustrações no texto, não suportam a idéia de precisar ler 'um livro inteiro'. A atenção e a concentração, a capacidade de abstração intelectual e de exercício do pensamento foram destruídas. Como esperar que possam desejar e interessar-se pelas obras de arte e de pensamento?

Entende-se que a liberdade e a capacidade de domínio de tempo e espaço promovidos pelos recursos disponibilizados pela Internet possibilitam aos usuários da informação uma idéia de falta de intermediação, uma idéia de não pre- sença de filtros e hierarquias. Pode-se constatar que essa mediação existe sendo imperceptível aos usuários. Nesse sentido, torna-se importante debater as questões pertinentes a esse novo conceito de comportamento do usuário, e, fundamentalmente, o papel do bibliotecário.

Não se pretende construir um discurso contra a Internet e as tecnologias da informação e comunicação, mas ao contrário, reconhecer que as novas tecnologias revolucionaram as relações entre os produtores, consumidores e intermediários da informação, modificando a forma tradicional do processo de comunicação do conhecimento, mas que a presença da intermediação humana é fundamental.

Froehlich (1998), Davenport (1998) e Wolton (2003), citados por Lopes e Silva (2006), são favoráveis à mediação humana. Para o primeiro a qualidade da informação pode ser comprometida sem a intermediação humana, pela falta de critérios de autoridade cognitiva como um sério problema para uso das fontes eletrônicas. Para o segundo, a informação, para ser valorizada, precisa ser organizada, reestruturada, interpretada e sintetizada, tarefas que as máquinas não fazem de forma satisfatória e as pessoas são os melhores meios para identificar, categorizar e integrar a informação. O terceiro ressalta a questão da competência no acesso, pois a possibilidade de acessar tudo, desde um supermercado até uma biblioteca, não desenvolve competência que garanta o acesso à informação, uma vez que isso requer estratégias mais elaboradas, isto é, saber procurar e o que procurar.

O processo de apropriação da informação e do conhecimento também é comprometido sem a mediação, segundo Targino (2000, p. 23), pois se agrava a tendência de horizontalização da leitura, o que compromete o processo, "esvai-se a probabilidade de uma visão totalizante do tema, e se abandona o interesse por obras densas, básicas ou de conteúdo clássico e vital à formação profissional em qualquer instância".

A mudança estrutural no fluxo da informação, do ambiente impresso para o ambiente eletrônico, transformou a relação do processo de mediação. Reconhece-se o deslocamento dos objetos, mas considera-se que o profissional tem um novo papel nessa nova rede de relação. O mediador tem o papel de agregar valor creditável nesse manancial de informações e serviços, oferecendo aos usuários uma informação com autoridade, sustentabilidade e valoração. 


\section{O mediador da informação no contexto da sociedade do conhecimento}

O papel do profissional da informação, no contexto da sociedade do conhecimento, é o da mediação que favorece a interação sujeito e objeto no desenvolvimento de competências, mas também como facilitador da apreensão do indivíduo.

Com base na teoria construtivista sóciohistórica, entende-se que a construção do conhecimento se dá nas relações de interação dialógicas estabelecidas pelo indivíduo. $\mathrm{O}$ profissional da informação tem sua ação no sentido de favorecer "a interação entre o sujeito e objeto do conhecimento e de facilitar a apreensão pelo indivíduo dos objetos físicos, inseridos, histórica e culturalmente, no contexto da rica rede de relações simbólicas que permeia o social" (Oddone, 1998, p. 7).

Para tanto, o profissional precisa entender seu novo papel como mediador nesse novo contexto. Volant $(1950$, citada por Oddone,1998) propõe sete eixos de ação nos quais o profissional deve transitar: o metodológico, o estratégico, o cognitivo, o pedagógico, o tecnológico, o econômico e o sócio-cultural. A articulação desses eixos atenderia a dinâmica do novo paradigma:

\section{Eixo Metodológico}

- Assegurando a coerência entre o sistema de informação global e os subsistemas locais, assim como a coerência dos métodos e das ferramentas;

- Permitindo a elaboração da "engenharia documentária".

\section{Eixo estratégico}

- Contribuindo para a definição de uma política de informação;

- Participando da reflexão estratégica da organização;

- Criando dinâmicas e contribuindo para a inovação.

\section{Eixo Cognitivo}

- Contribuindo para a resolução de problemas, para a fertilização do saber, para a abordagem interdisciplinar e para o questionamento.

\section{Eixo Pedagógico}

- Motivando os atores à utilização das informações;

- Formando os usuários na aplicação dos métodos e das técnicas de pesquisa e de tratamento da informação.

\section{Eixo tecnológico}

- Dominando as ferramentas;

- Adaptando os avanços tecnológicos para um uso apropriado.

6. Eixo Econômico

- Produzindo valor agregado;

- Prestando assessoria às esferas decisórias e operacionais da organização em suas necessidades informacionais.

\section{Eixo Sócio-Cultural}

- Contribuindo para a autonomia dos indivíduos e para a aprendizagem coletiva;

- Desenvolvendo uma verdadeira cultura da informação.

Será dada ênfase a três eixos que se consideram importantes para fomentar a discussão do ponto de vista da mediação: eixo cognitivo, eixo pedagógico e o eixo sócio-cultural.

O eixo de ação cognitivo propõe ao profissional agir favorecendo a contribuição para a resolução de problemas, a integração dos componentes para a construção do conhecimento, por meio da conciliação de conceitos, o questionamento. O eixo de ação pedagógico, a formação do usuário e o uso da informação. $O$ eixo de ação sócio-cultural, contribuindo para a autonomia dos indivíduos, desenvolvimento de habilidades e competências, aprendizagem.

Percebe-se nesses eixos de ação o novo papel do profissional da informação diante da nova estrutura: o papel de educador. Ele deixa para trás seu papel de passividade e isolamento chamando a atenção para um perfil dinâmico, questionador, de aprendizagem ao longo da vida. Se o advento da Internet e o uso das tecnologias da informação proporcionam a autonomia dos usuários, proporcionam também ao profissional o desenvolvimento da habilidade e da competência de ser um educador na Sociedade do Conhecimento, seu novo papel como mediador.

Segundo alguns estudos, com a difusão da internet e a multiplicidade de informações disponíveis a cada momento na rede, o usuário apresenta dificuldades em utilizar tudo que está disponível.

Vaz (2001, p. 57), citado por Lopes e Silva (2006) afirma que:

Talvez do ponto de global, possa-se dizer que a Internet gera uma sociedade mais complexa e diversa. Contudo, cada um de nós só pode percorrê-la de modo míope. Mais precisamente, esse potenci- 
al de diversidade global só encontra tradução no nível local dependendo da mediação.

O papel do profissional da informação é orientador, guiar, educar o usuário. O conceito de mediação seria definido como (Matui, 1995, apud Oddone, 1998, p. 7):

o processo de intervenção de elementos sóciosimbólicos, enquanto sistemas de representação da realidade [....] podemos identificar os mediadores do conhecimento por sua ação no sentido de favorecer a interação entre sujeito e objeto do conhecimento e de facilitar a apreensão pelo indivíduo dos objetos físicos inseridos, histórica e culturalmente, no contexto da rica rede de relações simbólicas que permeia o social. Entre diferentes artefatos que instrumentalizam, operacionalizam ou tornam apreensíveis essas múltiplas representações simbólicas, facilitando a aprendizagem, a apropriação e a construção do conhecimento, arrola livros, revistas, meios de comunicação de massa, assim como as ações deliberadamente voltadas nessa direção de certos indivíduos, como o professor e, sem dúvida, o bibliotecário, ou profissional da informação.

Nesse sentido, algumas ações precisam ser tomadas para que o profissional da informação exerça seu papel, sua função, na sociedade do conhecimento. Uma dessas ações seria a inclusão nas grades curriculares dos cursos de Biblioteconomia de disciplinas que contemplassem a interface com a área da Educação para que o profissional compreendesse sua ação de interferência na transmissão da informação para a apropriação do conhecimento no indivíduo. Estudos nesse sentido alavancariam a proposta do bibliotecário na perspectiva de educador no processo de mediação da informação.

\section{Considerações finais}

A Sociedade da Informação e do conhecimento vem imprimindo mudanças no papel do profissional da informação, tanto no que diz respeito ao desenvolvimento de novas competências e habilidades, como na postura profissional diante da nova comunicabilidade e sociabilidade.

A Internet e as tecnologias da informação colocaram em questão o papel mediador do profissional por meio do fenômeno da desintermediação que proporcionou a autonomia dos usuários na busca da informação em contraposição à intermediação tradicional com seus filtros e reguladores institucionais.

Mas, o conteúdo da Internet também é regulado, filtrado, controlado e administrado por empresas que visam à lucratividade $e$, por não estabelecerem uma presença real com os usuários, esses controladores invisíveis não são percebidos. A ausência da mediação compro- mete o processo de apropriação da informação, agravando a tendência de horizontalização da leitura, não permitindo a visão totalizante dos temas.

Reconhece-se a mudança estrutural no fluxo da informação e na relação do processo de mediação, mas também se defende que, atualmente, talvez mais do que em épocas passadas, o profissional da informação necessita estar presente como mediador na nova comunicabilidade, tendo papel de agregar valor creditável no manancial de informações e serviços oferecidos na nova Sociedade do Conhecimento, a partir da perspectiva de educador.

\section{Referências}

Chauí, Marilena (2006). Simulacro e poder: uma análise da mídia. São Paulo: Fundação Perseu Abramo, 2006.

Lévy, P. A. (2000). A revolução contemporânea em matéria de comunicação. // Martins, F. M.; Silva, J. M. da (Org.). Para navegar no século XXI: tecnologias do imaginário e cibercultura. 2.ed. Porto Alegre: Sulina, 2000. 195-216.

LIMA, Izabel França de et al. (2006). O bibliotecário na sociedade da informação e do conhecimento: perfil, competências e habilidades. // Seminário Nacional de Biliotecas Universitárias. 14 (2006). Salvador. Anais eletrônicos... Salvador: UFBA, 2006. http://www.snbu 2006.ufba.br/soac/viewabstract.php?id=105 (10 nov. 2006).

Lopes, Marili; Silva, Edna Lúcia da (2006). As bibliotecas universitárias e a mediação da informação na comunicação científica. // Seminário Nacional de Biliotecas Universitárias. 14 (2006). Salvador. Anais eletrônicos... Salvador: UFBA, 2006. http://www.snbu2006.ufba.br/soac/viewabstract.php?id=105 (10 nov. 2006).

Oddone, Nancy (1998). O profissional da informação e a mediação dos processos cognitivos: a nova face de um antigo personagem. Informação e Sociedade: estudos, Paraíba, s. 8:1 (1998). http://www.informacao esociedade.ufpb.br/ojs2/index.php/ies/article/viewFile/425/ 346 (10 nov. 2006)

Ramonet, Ignácio. O poder midiático. In.: Moraes, Denis de (Org.). Por uma outra comunicação: mídia, mundialização cultural e poder. Rio de Janeiro: Record, 2003. 243252.

Shera, Jessé H. Sobre biblioteconomia, documentação e ciência da informação. // Foskett, D. J. et. Ciência da informação ou informática? Rio de Janeiro: Calunga, 1980.

Targino, Maria das Graças (2000). Comunicação científica: uma revisão de seus elementos básicos. // Revista Informação \& Sociedade: estudos, João Pessoa. 10:2 (jul./dez. 2000). http://www.informacaoesociedade.ufpb. br/ojs2/index.php/ies/article/viewFile/326/248 (10 nov. 2006).

Vaz, Paulo (2001). Mediação e tecnologia. // Revista da FAMECOS, Porto Alegre. 16:1 (dez 2001) 45-58. http://www.pucrs.br/famecos/pos/revfamecos/16/a04v1n 16.pdf (10 nov. 2006). 